\title{
Post-lobectomy airways complications
}

\author{
Kate Wallwork, Elizabeth Belcher \\ Department of Thoracic Surgery, Oxford University Hospitals NHS Foundation Trust, Oxford, UK \\ Contributions: (I) Conception and design: All authors; (II) Administrative support: K Wallwork; (III) Provision of study materials or patients: None; (IV) \\ Collection and assembly of data: K Wallwork; (V) Data analysis and interpretation: None; (VI) Manuscript writing: All authors; (VII) Final approval \\ of manuscript: All authors. \\ Correspondence to: Elizabeth Belcher. Department of Thoracic Surgery, Oxford University Hospitals NHS Foundation Trust, Oxford, UK. \\ Email: Elizabeth.Belcher@ouh.nhs.uk.
}

\begin{abstract}
Post-lobectomy airways complications are associated with significant morbidity and mortality. Lobar torsion, bronchopleural fistula and bronchovascular fistula pose a challenge to the clinician to secure timely diagnosis and intervention in order to improve outcomes. We discuss the aetiology, presentation, prevention and management of lobar torsion, bronchopleural and bronchovascular fistula and anastomotic complications following lobar resection. Judicious surgical technique and effective employment of preventative strategies may reduce the risk of airway complications. Presentation of post-lobectomy airway complications may be non-specific but are often rapidly progressive. Computed tomography (CT) and bronchoscopy are essential diagnostic tools to support clinical suspicion. The pillars of successful management of post-lobectomy airway complications are a high degree of clinical suspicion, prompt investigation and early intervention. These are essential to minimise perioperative mortality and long-term sequelae. Minimal access surgery and novel endobronchial techniques have expanded the treatment options for post-lobectomy bronchial complications in selected patients.
\end{abstract}

Keywords: Lobectomy; torsion; bronchopleural fistula; stenosis

Received: 20 February 2020; Accepted: 23 March 2020; Published: 10 April 2021.

doi: $10.21037 /$ shc.2020.03.09

View this article at: http://dx.doi.org/10.21037/shc.2020.03.09

\section{Introduction}

Pulmonary lobectomy is an established life extending procedure with excellent peri-operative survival rates. Where bronchial complications are encountered however, morbidity and mortality are high. Lobar torsion, bronchopleural fistula, bronchovascular fistula and anastomotic complications pose a significant threat to survival in the early postoperative phase, with the potential for long term sequalae for survivors. Clinician familiarity with the risk factors, preventative techniques and management is essential in the expeditious diagnosis and management of these conditions.

In this review, we discuss the aetiology, presentation, prevention and management of post-lobectomy airway complications with a particular focus on lobar torsion, bronchopleural fistula, bronchovascular fistula, bronchial kinking, stenosis and anastomotic complications following bronchoplastic resection.

\section{Lobar torsion}

Lobar torsion is an uncommon but life-threatening complication of pulmonary lobectomy. Axial rotation of the remaining lobar parenchyma on its bronchovascular pedicle results in bronchial occlusion and vascular compromise (1-3). The incidence is between $0.09-0.4 \%$ (3-5). Upper lobectomy is responsible for almost $75 \%$ of cases with the right middle lobe being most vulnerable particularly following right upper lobectomy $(3,5,6)$. Left lower lobe torsion accounts for most of the remainder of cases however torsion has been reported in each lobe following lobectomy $(3,5,7,8)$. The degree of rotation in pulmonary torsion is 
generally $180^{\circ}$, although degrees of rotation between $70^{\circ}$ to beyond $360^{\circ}$ are reported (9-13), with two thirds rotating in a clockwise direction $(1,3)$.

The devastating clinical effects of torsion are due to simultaneous insults of pulmonary arterial, pulmonary venous and bronchial artery occlusion (2,3,6,14-16). Median time to diagnosis is four days (3) ranging from the day of operation up to three weeks $(5,17)$. A number of factors predispose a lobe to torsion by increasing its mobility, including a long, narrow or skeletonised bronchovascular pedicle $(1,3)$, complete oblique fissure (1), division of the inferior pulmonary ligament $(1,18)$, pleural air or fluid (1), an atelectatic or congested remaining lobe $(2,19)$ and the absence of adhesions (20).

A high index of suspicion is required to diagnose lobar torsion due to its tendency to mimic more common and often more benign postoperative complications such as pneumonia, atelectasis and sputum retention (13). Symptoms include dyspnoea (3), atypical chest pain $(3,21)$, cough (4), haemoptysis (6) or bronchorrhoea (22). Sudden cessation of previous air leak, lobar collapse, together with tachypnoea (15), fever (15), hypoxaemia refractory to oxygen therapy $(8,19)$, and leucocytosis should alert clinicians to consider lobar torsion $(3,4)$. Complete torsion may rapidly progress to sepsis and shock. The condition can however run an insidious course particularly in incomplete torsion and may even be asymptomatic (5).

Chest $x$-ray features of lobar torsion include rapidly progressive ipsilateral opacification in a lobar distribution, change in position of the lobe, inversion of vascular patterns and absence of mediastinal shift to the ipsilateral side (3). The computed tomography (CT) findings demonstrate poorly enhancing consolidation with increased volume, ground-glass attenuation and interlobular septal thickening. The affected lobe lies in an abnormal position in the hemithorax; at hilar level there is kinking of the pulmonary vessels and obliteration of the proximal bronchus (23-25). This curtailing of the lobar bronchus is described as the bronchial 'cut-off' sign $(26,27)$. A stapled horizontal fissure may be in contact with the right lower lobe (13). The 'Antler' sign is the abnormal curvature of the artery and its branches and is present in $40 \%$ of cases (28). Bronchoscopy may demonstrate a tortuous, narrowed, or a completely occluded bronchus with a 'fish-mouth' orifice $(3,7)$ and mucosal oedema (11). Where intubation of the torted bronchus is possible then recurrent bronchial collapse may occur on withdrawal of the bronchoscope. Bronchoscopic appearances are not always characteristic and lack of obvious torsion at bronchoscopy does not exclude the diagnosis.

Re-operation is indicated where suspicion of torsion remains. Care should be taken to avoid inadvertent or untimely detorsion, as this risks embolic events from thrombus in the pulmonary vein with subsequent systemic embolization $(4,10)$. Concomitant release of accumulated vasoactive mediators may also occur and can provoke a systematic inflammatory response ultimately leading to multiorgan failure and death (3). In the absence of features of infarction and gangrene, indicated by a blueblack appearance of the lobe, consideration may be given to returning the macroscopically viable lobe to its original position together with pneumopexy to the remaining lobe (on the right side), to the chest wall via a pleural flap, to the pericardium or to the main bronchus. Reported outcomes following detorsion are however variable. Repositioning may be attractive where a patient is at high risk from completion resection, however this remains controversial.

Even where the lobe appears viable, macroscopic appearances may be unreliable and the risk of embolic events and sepsis and its sequalae when the pulmonary vein is released remain. Resection reduces these risks $(7,15)$, and intrapericardial clamping of the pulmonary vein prior to its division is advised in order to prevent the release of thrombi and inflammatory mediators $(11,21)$. Lobar resection will be required in the majority of torsion patients due to non-viability (3). Based on the available evidence, where doubt exists as to the viability of the lobe, we advocate that resection should be undertaken, when residual pulmonary function permits. Whilst thoracotomy has traditionally been undertaken for torsion, video-assisted thoracoscopic surgery (VATS) can be utilized (15). Although successful conservative management of lobar torsion with steroids and non-invasive positive pressure ventilation (17) is reported, this is a high-risk strategy and we would not recommend conservative management where torsion is suspected.

There is a paucity of evidence on the predictors of survival in lobar torsion. A review performed by Dai et al. covering all reported cases over a 64-year period found an overall mortality rate of $8.3 \%$. There was no significant difference in mortality rates however, between resection without detorsion, resection after detorsion, and repositioning, although there was a trend towards poorer outcomes with indirect resection (3).

The practice of prophylactic fixation remains uncertain. Rates of prophylactic fixation range from $0.3-30 \%$ (29) and appear to be dependent on prior experience of torsion within the operating surgeons' practice (6). Rates of 
fixation where VATS is the now the preferred approach are uncertain. A number of prophylactic manoeuvres have been described. Suturing of the remaining right sided lobes either to each other (30) or remaining left sided lobe to the pericardium or to a posterior parietal pleural flap (31) are simple and cost-effective techniques. Disadvantages are increased operative time and risk of air leak and haemorrhage, but may be ameliorated by the use of glues, fleeces or membranes to facilitate pneumopexy $(29,32)$. Paucity of evidence outside of case reports means that conclusion on the efficiency of these techniques and the superiority of one technique over another is not possible however prophylactic fixation may be considered where a patient is considered to be at high risk of lobar torsion.

\section{Kinking}

Upper lobectomy results in upward displacement of the remaining lung and ipsilateral diaphragm. Whilst this movement facilitates obliteration of the pleural space, the displacement and subsequent change in the angle of the remaining bronchus may occur to an extent that kinking of the airway results $(33,34)$. Such kinking of the bronchus is most commonly seen after left upper lobectomy (35). Sigmoidal distortion of the left main bronchus results in cross sectional narrowing of the left lobar bronchus. Utilizing CT imaging analysis and computational fluid dynamics $\mathrm{Gu}$ et al. demonstrated that left upper lobectomy is associated with a significant reduction in the angle between the trachea and left main bronchus. This was associated with increased wall pressure, airflow velocity, sheer stress and turbulent flow at the site of kinking. The authors suggested that these changes may contribute to post-lobectomy negative adaptive remodelling that leads to symptoms of dyspnoea and cough in some patients (36).

Change in bronchial angle following upper lobectomy may be associated with reduced postoperative pulmonary function (37). Ueda et al. defined bronchial kinking as airway angulation and resultant stenosis exceeding $80 \%$. Postoperative functional lung volume and ventilatory capacity were significantly greater in patients without, than in those with bronchial kinking. Patients with bronchial kinking were more likely to experience intractable cough and shortness of breath $(76 \% v s .21 \%$, respectively, $\mathrm{P}<0.01)$ (33).

Symptomatic kinking may be difficult to diagnose where patient and clinician expects some breathlessness in the early postoperative phase and where patients differ in their recovery times. Changes in bronchial angle in a patient who is slow to recover may not be causative. Furthermore, significant radiological kinking may remain subclinical (33). In a series of 50 patients undergoing upper lobectomy, almost one quarter of patients with angulation and resultant stenosis exceeding $80 \%$ remained asymptomatic (33). However, symptoms of cough and breathlessness beyond six months may be attributable to kinking $(33,38)$.

The role of preoperative patient factors and technical intraoperative manoeuvres in the development of kinking is uncertain. Masuda et al. identified that a shorter distance from the carina to the middle lobe may be associated with kinked middle lobar bronchus (39). The post-lobectomy bronchial angle may be influenced by a number of anatomical and technical factors including the degree of diaphragmatic elevation, extent of mediastinal shift, effect of nodal dissection on hilar release and whether division of the inferior pulmonary ligament is undertaken. Proposed advantages of inferior pulmonary ligament division include reduction in risk of residual space and its consequences of pleural effusion, empyema and prolonged air leak. Whilst some studies have demonstrated that preservation of the inferior pulmonary ligament at upper lobectomy is associated with reduction in change of the bronchial angle and better lung function compared to those who undergo division (40), others have noted no difference in bronchial angle or pulmonary function when comparing division and preservation of the ligament $(41,42)$. Differences in findings may be due to the small number of patients in the studies or due to the variation in the modality of imaging utilised to calculate the bronchial angle. In a recent systematic review and meta-analysis of the necessity of inferior pulmonary ligament dissection after an upper lobectomy, the pooled comparison revealed a greater change of the right main bronchial angle (MD 5.00, 95\% CI: 1.68 to $8.33, \mathrm{P}=0.003$ ) in the group undergoing inferior pulmonary ligament division (43). This collective evidence, together with experience of a case of bronchial kinking in a patient with previous hilar release has influenced a change in the authors practice where lobectomy is performed with preservation of the inferior pulmonary ligament.

There is no consensus on the optimal treatment of postlobectomy bronchial kinking with evidence of treatment of symptomatic patients limited to case reports. Endobronchial stenting has been successfully employed in a small number of patients $(44,45)$. Figure 1 shows kinking following right upper lobectomy in a patient at our institution who had previously undergone oesophagectomy. The patient was severely symptomatic with breathlessness and stridor. 

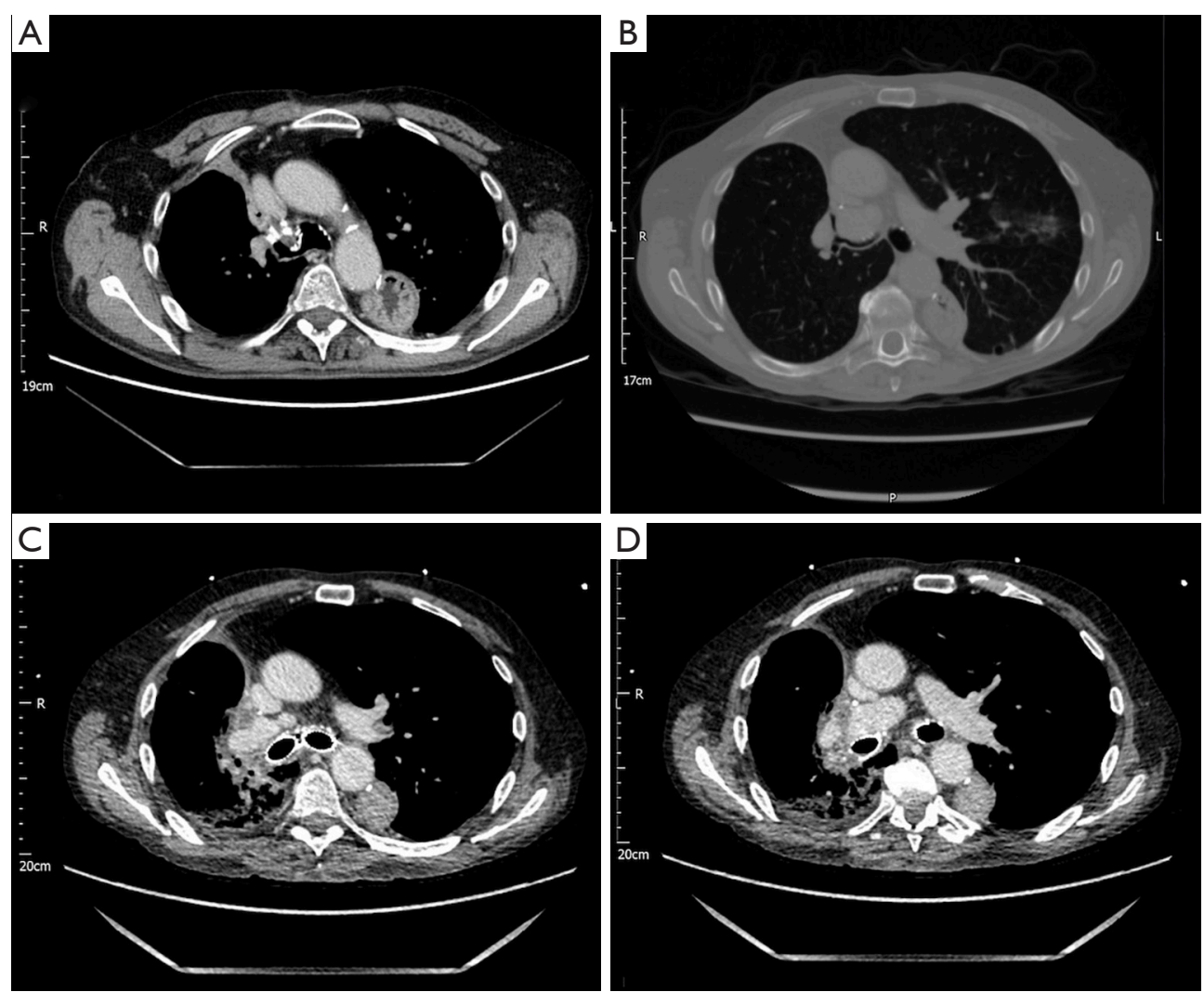

Figure 1 CT images showing kinking of the bronchus intermedius (A,B) following right upper lobectomy in a patient with a previous oesophagectomy. (C) and (D) show successful treatment with a metal expandable Y stent.

Temporary stenting was undertaken with benefit. Where stenosis is severe with collapse or where torsion cannot be excluded, re-exploration with VATS should be the first line to exclude torsion and facilitate repositioning of the lobe, bronchopexy to the pericardium and repair of inferior pulmonary ligament which may provide symptomatic improvement (34).

\section{Bronchopleural fistula}

Post-lobectomy bronchopleural fistula (BPF) occurs due to partial or complete dehiscence of the bronchial stump and results in communication between the airway and the pleural space. Life threatening sequelae may ensue including empyema, sepsis, aspiration pneumonia and acute respiratory distress syndrome (ARDS) $(27,46)$.

The reported incidence of $\mathrm{BPF}$ after lobectomy is $0.5 \%$ $(47,48)$. The incidence is higher following bilobectomy (2.2\%), sleeve resection (2.8\%) (49) and pneumonectomy $(3-5 \%)(48,50)$. In addition to the type of resection, patient factors and intra-operative factors are implicated. Patient factors include malnutrition, smoking, chronic obstructive airways disease (51), inflammatory disease, immunosuppression, diabetes mellitus and prolonged ventilation $(48,51,52)$. With regards to technical aspects, although most studies show no difference in the rates of BPF between manual and stapled closure, there appears to be greater variability with manual closure $(1.5-12.5 \%$ vs. $1-5.7 \%)$, and surgeon inexperience influences the rate of BPF (53). Incomplete resection (51) and long bronchial stump (54) have also been shown to increase risk of BPF. In a large series of post-resection BPF, lymph node dissection did not increase its incidence $(48,54)$. Right sided resections are associated with a higher risk and fistula occurs most commonly after right lower lobectomy $(47,48,55)$. Comparatively less mediastinal coverage and anatomical variation of bronchial arterial supply is thought to account for this $(27,46)$.

BPF can be classified as early ( $<7$ days), intermediate (7-30 days) or late ( $>30$ days) (56). Early fistulae are related 
to technical error, whereas intermediate and late fistulae are mostly attributable to impaired healing of the bronchial stump (56). Cardillo et al. reported that $76.9 \%$ of BPF develop <30 days postoperatively (57).

Both neoadjuvant radiotherapy and chemoradiation significantly increased the BPF risk, however neoadjuvant chemotherapy does not $(58,59)$. In a multivariate analysis of a national database of patients undergoing pulmonary resection, sex, body mass index, dyspnea score, number of comorbidities, bilobectomy, pneumonectomy, emergency surgery, sleeve resection, and side of the resection influenced risk of BPF (48). The main cause of death in $\mathrm{BPF}$ is aspiration pneumonia and ARDS (52). Whilst the incidence of $\mathrm{BPF}$ is lower following lobectomy rather than pneumonectomy, once BPF is established the mortality appears to be independent of the type of resection, with mortality rates of lobectomy associated $\mathrm{BPF}$ of $25 \%$ versus $20 \%$ for pneumonectomy (48).

The clinical presentation of BPF is dependent on its size, timing from surgery and the presence or absence of empyema. Early technical failure may present with sudden large volume air leak and cardiorespiratory deterioration. Presentation within the first few postoperative weeks is associated with cough, purulent sputum, pleuritic chest pain, fever, leucocytosis and purulent output from the drain (46).

Radiological findings in post-lobectomy BPF include new or increased hydropneumothorax and mediastinal shift towards pre-resection position (27). The less common situation of sudden early stump failure may present with tension pneumothorax. The fistula may not be directly visible on CT but is suggested by the presence of air locules adjacent to the bronchial stump (27). Bronchoscopy allows direct visualisation of the fistula, assessment of size and the quality of the bronchial stump mucosa. Instillation of saline can assist diagnosis of small fistulae.

By virtue of a more distal site, the post-lobectomy BPF is generally smaller than those following pneumonectomy. Conservative management of small fistulae may be amenable to chest drainage as a definite procedure $(60,61)$ however for the majority of patients with significant fistula, surgical management is the mainstay of treatment. The principles of BPF management are control of infection via pleural drainage, antibiotics, and closure of the fistula. Drainage, deloculation, debridement and decortication of the residual lung are the principles of surgery for associated empyema. Bronchial stump primary closure may be possible, however further resection of the bronchial stump may be required where necrosis is present and length of bronchial stump permits (46).

Buttressing of the stump with a tension-free vascularized pedicled flap $(46,62)$ should be considered. This aims to increase the blood supply to the stump and has been described using intercostal $(63)$, latissimus dorsi $(64,65)$ or serratus anterior muscle flaps $(66,67)$, pectoralis major and diaphragm flaps $(46,68)$, omentopexy $(69,70)$ thymic flap (71), pericardial fat pad (72) and pleural flap (73). Figure 2 shows CT images of a patient who developed BPF following bilobectomy. Re-operation, primary closure, buttressing with intercostal muscle, obliteration of the pleural space using pedicled serratus anterior and pectoralis muscle flap was performed. Where the above techniques fail, open window thoracostomy can be considered for management of sepsis if mediastinum is fixed. Thoracoplasty may be considered for recurrent cases. Operative mortality is 3.8\% to $5.1 \%(57,74)$ with surgical cure rates between $88-90 \%$ $(57,75)$.

In patients where the risk of repeat surgery is unacceptably high, the literature supports endoscopic intervention as definitive treatment or bridging therapy. Bronchoscopic treatment with various techniques to close smaller fistulae $<8 \mathrm{~mm}$ have been described (76) with the potential advantages of avoidance of operation and lower cost $(60,61)$. Numerous agents have been employed including tissue glues $(77-80)$, metallic coils $(81,82)$, stents (83-87), endobronchial one-way valves (88-91) and the Watanabe Spigot (92), expandable resorbable sponges, patches or mesh (93-95) or submucosal sclerosant injection (96) with success rates ranging from 33\% to $100 \%$. Caution as to the added efficacy of these techniques is advised however when noting a study comparing conservative treatment and conservative plus endoscopic treatment, which found no significant difference in the mean time to resolution of BPF between the two groups (97). Use of an Amplatzer device (AGA Medical Corporation, Plymouth, USA) for post-lobectomy fistula (98-104) has also been described.

Vacuum assisted closure (VAC), as an adjunct to conventional management, may reduce morbidity and reduce treatment times in patients with BPF with empyema. Stimulation of angiogenesis and fibroblasts facilitates repair over time. A review and meta-analysis of patients undergoing vacuum therapy showed VAC was associated with reduced morbidity, hospital stay and total length of treatment (105). VAC appears safe in patients with residual lung in situ (106). 

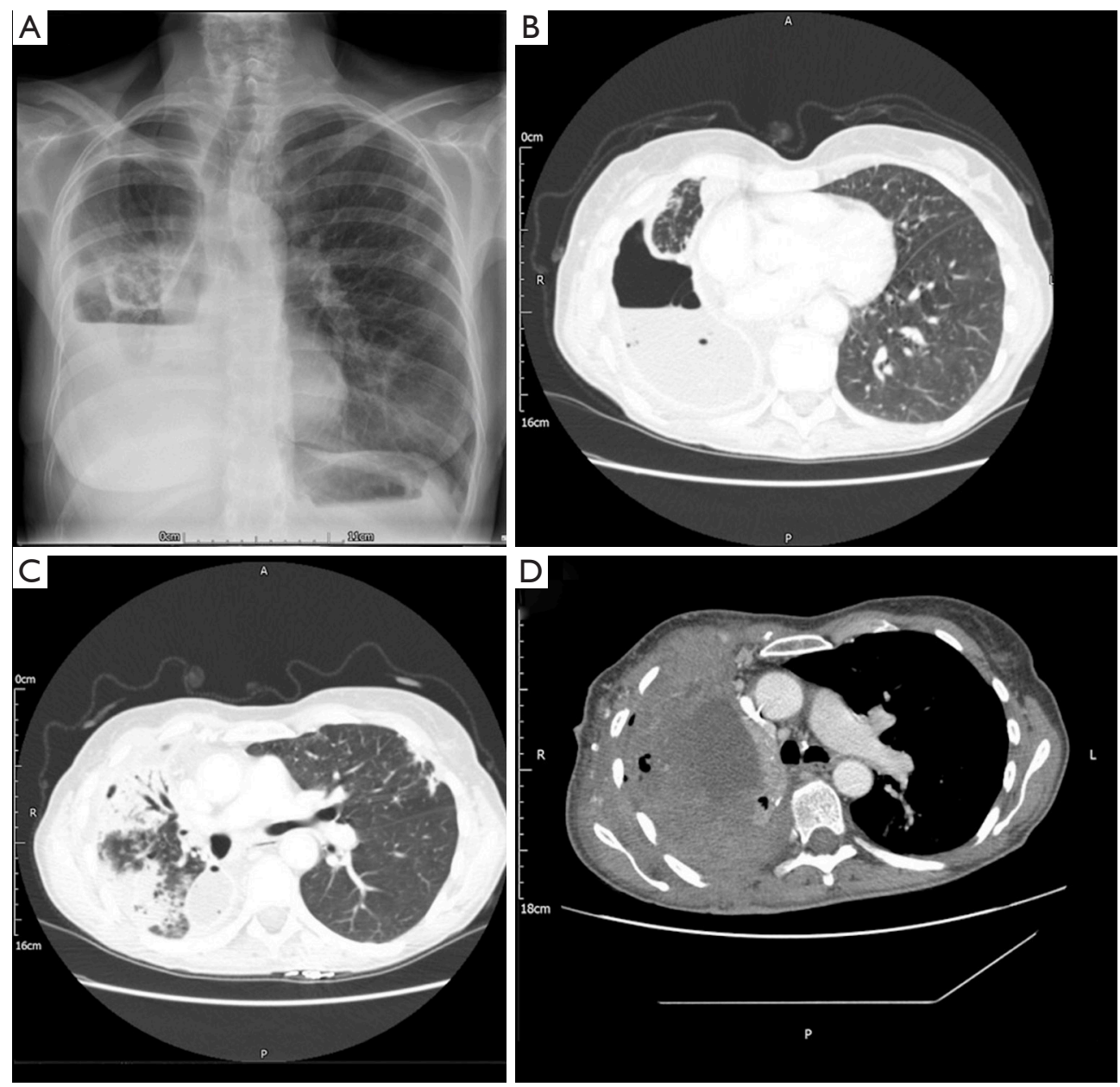

Figure 2 CT images of a BPF following bilobectomy with hydropneumothorax (A,B) and its resolution with re-operation, primary repair of the fistula and serratus anterior and pectoralis major muscle flaps (C,D).

A number of techniques aimed at the prevention of BPF have been proposed including pleural, diaphragmatic, intercostal muscle and azygous vein adjuncts to the bronchial stump $(107,108)$. Non-randomised studies show variable benefits of autologous bronchial stump adjuncts (108). Whilst bronchial stump reinforcement is advocated during repair of a $\mathrm{BPF}$, there is inadequate evidence to recommend routine bronchial stump buttressing following lobectomy. Where a patient is considered high risk for BPF such as those receiving neoadjuvant radiotherapy, bronchial stump reinforcement may be reasonable.

\section{Bronchovascular fistula}

Bronchovascular fistula is a devastating complication arising as a consequence of asymptomatic peri-anastomotic inflammation of the bronchus and subsequent septic erosion and rupture of the adjacent pulmonary vessel wall $(73,109)$. The result is massive haemorrhage into the airway with a mortality rate which approaches $100 \%$ $(73,110-113)$. Bronchopleural fistula is implicated as the most significant cause of bronchovascular fistula, where preceding bronchopleural fistula, either clinically apparent or asymptomatic, but with significant inflammation around the bronchial stump causes erosion of the adjacent wall of the pulmonary artery. Mean time to presentation is four weeks postoperatively (range $2-24$ weeks), and over $80 \%$ of cases present within eight weeks (113).

Bronchovascular fistula may be seen after simple lobectomy (114) but most frequently complicates bronchoplastic sleeve resection with an incidence of approximately $2 \%(110,115,116)$. The majority of cases of 
bronchovascular fistula occur after upper lobectomy with over half after right upper lobe resection and approximately one third after left upper lobectomy (113).

Due to rapidly fatal haemoptysis the rate of surgical intervention is as low as approximately $10 \%$ $(111,112,117,118)$. Where time permits, management involves urgent bronchoscopy to confirm diagnosis and emergency surgery with proximal control of the bronchus and vessel and completion pneumonectomy $(73,117,118)$. Massive haemoptysis may be preceded by a 'sentinel bleed'. Successful endovascular stenting has been described for pulmonary artery to bronchial stump fistula presenting three months after right upper lobectomy (114). Whether preventative techniques can reduce the incidence of bronchovascular fistula after lobectomy is uncertain. Hilar dissection and individual ligation of hilar structures is advocated to reduce the incidence, however in a series of 400 patients undergoing simultaneously stapled en masse lobectomy, no cases of bronchovascular fistula occurred (119). Autologous wrapping of anastomotic site to provide a barrier between the bronchial anastomosis and vascular tissue has been utilised in an attempt to reduce the risk of bronchovascular fistula. Circumferential placement of parietal pleural flap, pericardial fad pad or intercostal muscle separates the bronchial and vascular planes with viable tissue $(73,120,121)$.

\section{Anastomotic stenosis}

Bronchial stenosis after bronchoplastic resection is seen in $2-6 \%$ of patients $(50,73,110,115,122)$. The aetiology of bronchial stenosis after sleeve resection may be ischaemic in origin or may occur as a result of wedge excision. Such excision leads to loss of cartilaginous support and stenosis may arise directly from bulging into the bronchial lumen (50) or indirectly due to formation of dense scar tissue secondary to compromised bronchial mucosal healing $(73,110,123)$.

Asymptomatic non-severe stenoses should be managed conservatively with bronchoscopic monitoring $(73,123)$ with intervention indicated for cases of secondary recurrent pneumonia, lobar collapse or severe stenoses (73). Early anastomotic revision may be required where presentation is in the early postoperative phase (124). Late bronchial stenosis is managed by bronchoscopic dilation $(49,124)$, laser therapy $(125)$ or stenting $(73,112,115,123,126)$. Failure to maintain patency with dilatation or laser recanalization is as high as $50 \%$ (123), and repeat procedures are required $(110,123,127)$. As such we advocate bronchial dilatation in combination with stenting where anatomically possible. Stenting may however be challenging due to the short length of the main bronchus and proximity of segmental bronchi to the anastomosis (123).

In cases of severe stenosis or where endoscopic treatment has failed resection of the stenotic segment and redo anastomosis is required $(73,127)$. Completion pneumonectomy may be necessary where segmental resection is not feasible or where the remaining lung is nonviable $(73,110,112,118,122)$.

\section{Prevention of anastomotic complications following bronchoplastic resection}

Bronchopleural fistula, bronchovascular fistula and stenosis occur most frequently as anastomotic complications following sleeve lobectomy. They account for the majority of associated late morbidity and mortality and have a combined incidence in excess of $20 \%$ (123). A number of management strategies have been proposed to help reduce the risk. Bronchoscopic assessment of resectability including biopsy of areas proximal and distal to the tumour balance the competing risks of complete resection versus provision of a tension free anastomosis via minimising length of bronchial resection $(73,127)$. Assessment of nodal disease with endobronchial ultrasound may demonstrate bronchial infiltration, not apparent at bronchoscopy and assist in ensuring complete resection $(73,127)$. Weaning of corticosteroids prior to resection may also reduce the risk of anastomotic complications (73).

Meticulous surgical technique is important in minimizing the risk of anastomotic complications. Preservation of tracheobronchial blood supply by avoidance of excessive dissection or diathermy, careful lymph node dissection and tension free anastomosis all help reduce the risks of bronchial mucosal ischaemia implicated in the development of anastomotic complications $(73,110,127,128)$. Intraoperative frozen section analysis can assist in the competing luminal requirements for complete resection versus tension free anastomosis $(110,121)$. Placement of extra-luminal knots (118) and compensation for calibre mismatch during fashioning of the bronchial anastomosis are advocated $(73,121)$. Buttressing of the anastomosis with autologous pedicled vascularized tissue e.g., pedicled pericardial fat, pleura $(120)$, or intercostal muscle $(73,121)$ may reduce the risk of anastomotic breakdown and its sequalae. Release 
manoeuvres can avoid tension at the anastomotic site via division of the inferior pulmonary ligament $(118,120,127)$ and hilar release using a pericardial incision around the inferior pulmonary vein $(118,123,127)$.

Administration of postoperative low-dose steroids has been advocated with the aim reducing oedema, granuloma formation and subsequent dehiscence (121). Ludwig et al. have proposed utilizing inhaled Tobramycin to reduce the rate of anastomotic insufficiency via infection prevention (109). Bronchoscopic evaluation of the anastomosis site in the early postoperative phase, may allow early identification of anastomotic compromise following sleeve resection $(73,109,128)$.

\section{Conclusions}

Airway complications following conventional or bronchoplastic lobectomy pose a significant risk to patients due to their devastating sequelae. Diagnosis of bronchial complications after lobectomy can be challenging due to their tendency to mimic other more common and less serious postoperative complications. Clinical suspicion is therefore imperative in order that early intervention can alter the outcome of these conditions. Lack of guidelines outlining optimal management means that clinicians rely on clinical expertise and available evidence to make tailored decisions regarding best management. Meticulous surgical technique and employment of preventative strategies, particularly in those considered to be high risk, may reduce the risk of airway complications. Some of these techniques remain controversial with conflicting or lowquality evidence. Ongoing research is required to establish optimal preventative strategies and management of airway complications after lobectomy.

\section{Acknowledgments}

Funding: None.

\section{Footnote}

Provenance and Peer Review: This article was commissioned by the Guest Editor (David Waller) for the series "Complications of Thoracic Surgery-aetiology, management and prevention" published in Shanghai Chest. The article has undergone external peer review.

Conflicts of Interest: Both authors have completed the
ICMJE uniform disclosure form (available at http://dx.doi. org/10.21037/shc.2020.03.09). The series "Complications of Thoracic Surgery-aetiology, management and prevention" was commissioned by the editorial office without any funding or sponsorship. The authors have no other conflicts of interest to declare.

Ethical Statement: The authors are accountable for all aspects of the work in ensuring that questions related to the accuracy or integrity of any part of the work are appropriately investigated and resolved. Written informed consent was obtained from the patient for publication of this manuscript and any accompanying images.

Open Access Statement: This is an Open Access article distributed in accordance with the Creative Commons Attribution-NonCommercial-NoDerivs 4.0 International License (CC BY-NC-ND 4.0), which permits the noncommercial replication and distribution of the article with the strict proviso that no changes or edits are made and the original work is properly cited (including links to both the formal publication through the relevant DOI and the license). See: https://creativecommons.org/licenses/by-nc-nd/4.0/.

\section{References}

1. Felson B. Lung torsion: radiographic findings in nine cases. Radiology 1987;162:631-8.

2. Farkas EA, Detterbeck FC. Airway complications after pulmonary resection. Thorac Surg Clin 2006;16:243-51.

3. Dai J, Xie D, Wang H, et al. Predictors of survival in lung torsion: A systematic review and pooled analysis. J Thorac Cardiovasc Surg 2016;152:737-745.e3.

4. Cable DG, Deschamps C, Allen MS, et al. Lobar torsion after pulmonary resection: presentation and outcome. J Thorac Cardiovasc Surg 2001;122:1091-3.

5. Taira N, Kawasaki H, Takahara S, et al. Postoperative Lung Torsion With Retained Viability: The Presentation and Surgical Indications. Heart Lung Circ 2018;27:849-52.

6. Wong PS, Goldstraw P. Pulmonary torsion: a questionnaire survey and a survey of the literature. Ann Thorac Surg 1992;54:286-8.

7. Alassar A, Marchbank A. Left lower lobe torsion following upper lobectomy-prompt recognition and treatment improve survival. J Surg Case Rep 2014;2014:rju078.

8. Mansour W, Moussaly E, Abou Yassine A, et al. Left Lung Torsion: Complication of Lobar Resection for an 
Early Stage Lung Adenocarcinoma. Case Rep Crit Care 2016;2016:9240636.

9. Matsui H, Mizuno T, Sano M, et al. [Torsion of the middle lobe after right upper lobectomy: a case report]. Kyobu Geka 1993;46:1073-6.

10. Apostolakis E, Koletsis EN, Panagopoulos N, et al. Fatal stroke after completion pneumonectomy for torsion of left upper lobe following left lower lobectomy. J Cardiothorac Surg 2006;1:25.

11. Sakai M, Kurimori K, Saeki Y, et al. Video-assisted thoracoscopic conservative repair of postoperative lobar torsion. Ann Thorac Surg 2014;98:e119-21.

12. Wang X, Chen X, Ding Z, et al. Detorsion of the Pulmonary Torsion: A Rare Post-thoracotomy Complication. Heart Lung Circ 2016;25:e62-3.

13. Yanagihara T, Ichimura H, Kobayashi K, et al. Computed tomography detection of stapled interlobar fissure facilitates diagnosing postoperative lobar torsion: A case report. Int J Surg Case Rep 2017;41:86-8.

14. Schamaun M. Postoperative pulmonary torsion: report of a case and survey of the literature including spontaneous and posttraumatic torsion. Thorac Cardiovasc Surg 1994;42:116-21.

15. Sung HK, Kim HK, Choi YH. Re-thoracoscopic surgery for middle lobe torsion after right upper lobectomy. Eur J Cardiothorac Surg 2012;42:582-3.

16. Liebow AA, Hales MR, Harrison W, et al. The genesis and functional implications of collateral circulation of the lungs. Yale J Biol Med 1950;22:637-50.

17. Nakada T, Tsukamoto Y, Yabe M, et al. Right Upper Lobe Torsion after Right Lower Lobectomy: A Rare and Potentially Life-Threatening Complication. Case Rep Pulmonol 2018;2018:2146458.

18. Jones JM, Paxton LD, Graham AN. Acute postoperative lobar torsion associated with pulmonary arterial rupture. J Thorac Cardiovasc Surg 2003;126:303.

19. Childs L, Ellis S, Francies O. Pulmonary lobar torsion: a rare complication following pulmonary resection, but one not to miss. BJR Case Rep 2016;3:20160010.

20. Schuler JG. Intraoperative lobar torsion producing pulmonary infarction. J Thorac Cardiovasc Surg 1973;65:951-5.

21. Kucich VA, Villarreal JR, Schwartz DB. Left upper lobe torsion following lower lobe resection. Early recognition of a rare complication. Chest 1989;95:1146-7.

22. Ziarnik E, Grogan EL. Postlobectomy Early Complications. Thorac Surg Clin 2015;25:355-64.

23. Spizarny DL, Shetty PC, Lewis JW, Jr. Lung torsion: preoperative diagnosis with angiography and computed tomography. J Thorac Imaging 1998;13:42-4.

24. Gilkeson RC, Lange P, Kirby TJ. Lung torsion after lung transplantation: evaluation with helical CT. AJR Am J Roentgenol 2000;174:1341-3.

25. Niekel MC, Horsch AD, Ven M, et al. Right middle lobe torsion: evaluation with CT angiography. Emerg Radiol 2009;16:387-9.

26. Nömayr A, Schmitt R, Rupprecht H, et al. Postoperative pulmonary torsion and hemorrhagic lung infarct--report of a case. Rontgenpraxis 1998;51:430-2.

27. Kim EA, Lee KS, Shim YM, et al. Radiographic and CT findings in complications following pulmonary resection. Radiographics 2002;22:67-86.

28. Hammer MM, Madan R. Clinical and imaging features in lung torsion and description of a novel imaging sign. Emerg Radiol 2018;25:121-7.

29. Higashiyama M, Takami K, Higaki N, et al. Pulmonary middle lobe fixation using TachoComb in patients undergoing right upper lobectomy with complete oblique fissure. Interact Cardiovasc Thorac Surg 2004;3:107-9.

30. Duan L, Chen X, Jiang G. Lobar torsion after videoassisted thoracoscopic lobectomy: 2 case reports. Thorac Cardiovasc Surg 2012;60:167-9.

31. Kutlu CA, Olgac G. Pleural flap to prevent lobar torsion: A novel technique. Eur J Cardiothorac Surg 2006;30:943-4.

32. Le Pimpec-Barthes F, Arame A, Pricopi C, et al. Prevention of middle lobe torsion or bronchial plication using anti-adhesive membrane: a simple, safe and uncomplicated technique! Eur J Cardiothorac Surg 2011;39:1059-60.

33. Ueda K, Tanaka T, Hayashi M, et al. Clinical ramifications of bronchial kink after upper lobectomy. Ann Thorac Surg 2012;93:259-65.

34. Kim MS, Hwang Y, Kim HS, et al. Reverse v-shape kinking of the left lower lobar bronchus after a left upper lobectomy and its surgical correction. Korean J Thorac Cardiovasc Surg 2014;47:483-6.

35. Nonaka M, Kadokura M, Yamamoto S, et al. Analysis of the anatomic changes in the thoracic cage after a lung resection using magnetic resonance imaging. Surg Today 2000;30:879-85.

36. Gu Q, Qi S, Yue Y, et al. Structural and functional alterations of the tracheobronchial tree after left upper pulmonary lobectomy for lung cancer. Biomed Eng Online 2019;18:105.

37. Seok Y, Cho S, Lee JY, et al. The effect of postoperative change in bronchial angle on postoperative pulmonary 
function after upper lobectomy in lung cancer patients. Interact Cardiovasc Thorac Surg 2014;18:183-8.

38. Bolliger CT, Jordan P, Soler M, et al. Pulmonary function and exercise capacity after lung resection. Eur Respir J 1996;9:415-21.

39. Masuda Y, Marutsuka T, Suzuki M. A risk factor for kinked middle lobar bronchus following right upper lobectomy. Asian Cardiovasc Thorac Ann 2014;22:955-9.

40. Kim DH, Moon DH, Kim HR, et al. Effect of inferior pulmonary ligament division on residual lung volume and function after a right upper lobectomy. Interact Cardiovasc Thorac Surg 2019;28:760-6.

41. Bu L, Yang AR, Peng H, et al. Dividing inferior pulmonary ligament may change the bronchial angle. J Surg Res 2016;201:208-12.

42. Matsuoka H, Nakamura H, Nishio W, et al. Division of the pulmonary ligament after upper lobectomy is less effective for the obliteration of dead space than leaving it intact. Surg Today 2004;34:498-500.

43. Lv H, Zhou R, Zhan X, et al. The choice of dissection or preservation of the inferior pulmonary ligament after an upper lobectomy: a systematic review and meta-analysis. World J Surg Oncol 2020;18:5.

44. Mueller DK, Foiles SR. Right mainstem bronchial kink after right upper lobectomy. Ann Thorac Surg 2007;84:1401.

45. Van Leuven M, Clayman JA, Snow N. Bronchial obstruction after upper lobectomy: kinked bronchus relieved by stenting. Ann Thorac Surg 1999;68:235-7.

46. Zanotti G, Mitchell JD. Bronchopleural Fistula and Empyema After Anatomic Lung Resection. Thorac Surg Clin 2015;25:421-7.

47. Cerfolio RJ. The incidence, etiology, and prevention of postresectional bronchopleural fistula. Semin Thorac Cardiovasc Surg 2001;13:3-7.

48. Pforr A, Pages PB, Baste JM, et al. A Predictive Score for Bronchopleural Fistula Established Using the French Database Epithor. Ann Thorac Surg 2016;101:287-93.

49. Gonzalez M, Litzistorf Y, Krueger T, et al. Impact of induction therapy on airway complications after sleeve lobectomy for lung cancer. Ann Thorac Surg 2013;96:247-52.

50. Lee ES, Park SI, Kim YH, et al. Comparison of operative mortality and complications between bronchoplastic lobectomy and pneumonectomy in lung cancer patients. J Korean Med Sci 2007;22:43-7.

51. Li SJ, Zhou XD, Huang J, et al. A systematic review and meta-analysis-does chronic obstructive pulmonary disease predispose to bronchopleural fistula formation in patients undergoing lung cancer surgery? J Thorac Dis 2016;8:1625-38.

52. Sirbu H, Busch T, Aleksic I, et al. Bronchopleural fistula in the surgery of non-small cell lung cancer: incidence, risk factors, and management. Ann Thorac Cardiovasc Surg 2001;7:330-6.

53. Zakkar M, Kanagasabay R, Hunt I. No evidence that manual closure of the bronchial stump has a lower failure rate than mechanical stapler closure following anatomical lung resection. Interact Cardiovasc Thorac Surg 2014;18:488-93.

54. Sonobe $M$, Nakagawa $M$, Ichinose $M$, et al. Analysis of risk factors in bronchopleural fistula after pulmonary resection for primary lung cancer. Eur J Cardiothorac Surg 2000;18:519-23.

55. Boudaya MS, Smadhi H, Zribi H, et al. Conservative management of postoperative bronchopleural fistulas. J Thorac Cardiovasc Surg 2013;146:575-9.

56. Varoli F, Roviaro G, Grignani F, et al. Endoscopic treatment of bronchopleural fistulas. Ann Thorac Surg 1998;65:807-9.

57. Cardillo G, Carbone L, Carleo F, et al. The Rationale for Treatment of Postresectional Bronchopleural Fistula: Analysis of 52 Patients. Ann Thorac Surg 2015;100:251-7.

58. Li S, Fan J, Liu J, et al. Neoadjuvant therapy and risk of bronchopleural fistula after lung cancer surgery: a systematic meta-analysis of 14912 patients. Jpn J Clin Oncol 2016;46:534-46.

59. Brunelli A, Rocco G, Szanto Z, et al. Morbidity and mortality of lobectomy or pneumonectomy after neoadjuvant treatment: an analysis from the ESTS database. Eur J Cardiothorac Surg 2020;57:740-6.

60. Naranjo Gómez JM, Carbajo Carbajo M, Valdivia Concha $\mathrm{D}$, et al. Conservative treatment of post-lobectomy bronchopleural fistula. Interact Cardiovasc Thorac Surg 2012;15:152-4.

61. Mao R, Ying PQ, Xie D, et al. Conservative management of empyema-complicated post-lobectomy bronchopleural fistulas: experience of consecutive 13 cases in 9 years. J Thorac Dis 2016;8:1577-86.

62. Scarci M, Abah U, Solli P, et al. EACTS expert consensus statement for surgical management of pleural empyema. Eur J Cardiothorac Surg 2015;48:642-53.

63. Sfyridis PG, Kapetanakis EI, Baltayiannis NE, et al. Bronchial stump buttressing with an intercostal muscle flap in diabetic patients. Ann Thorac Surg 2007;84:967-71. 64. Abolhoda A, Bui TD, Milliken JC, et al. Pedicled 
latissimus dorsi muscle flap: routine use in high-risk thoracic surgery. Tex Heart Inst J 2009;36:298-302.

65. Nakajima Y, Akiyama H, Kinoshita H, et al. Two Cases of Single-Stage Closure of a Bronchopleural Fistula Using Latissimus Dorsi Musculocutaneous Flaps after Lung Surgery. Ann Thorac Cardiovasc Surg 2015;21:496-9.

66. Meyer AJ, Krueger T, Lepori D, et al. Closure of large intrathoracic airway defects using extrathoracic muscle flaps. Ann Thorac Surg 2004;77:397-404; discussion 405.

67. Park JS, Eom JS, Choi SH, et al. Use of a serratus anterior musculocutaneous flap for surgical obliteration of a bronchopleural fistula. Interact Cardiovasc Thorac Surg 2015;20:569-74.

68. Mineo TC, Ambrogi V. The diaphragmatic flap: A multiuse material in thoracic surgery. J Thorac Cardiovasc Surg 1999;118:1084-9.

69. Endoh H, Yamamoto R, Nishizawa N, et al. Thoracoscopic surgery using omental flap for bronchopleural fistula. Surg Case Rep 2019;5:5.

70. D'Andrilli A, Ibrahim M, Andreetti C, et al. Transdiaphragmatic harvesting of the omentum through thoracotomy for bronchial stump reinforcement. Ann Thorac Surg 2009;88:212-5.

71. Wilson MA, Seder C, O'Donnell ME, et al. Thymic flap for bronchial stump reinforcement after lobectomy. Ann Thorac Surg 2015;99:1071-3.

72. Uramoto H, Nakajima $Y$, Kinoshita H. Is the Isolated Pericardial Fat Pad Sufficient to Cover the Bronchial Stump and Separate the Pulmonary Artery in Order to Prevent Bronchopleural Fistula in Patients with Lung Cancer? Anticancer Res 2016;36:2385-9.

73. Tapias LF, Ott HC, Mathisen DJ. Complications Following Carinal Resections and Sleeve Resections. Thorac Surg Clin 2015;25:435-47.

74. Yang Y, Gao W, Zhao H, et al. Risk factors and consequences of perioperative reoperation in patients undergoing pulmonary resection surgery. Surgery 2016;159:591-601.

75. Massera F, Robustellini M, Della Pona C, et al. Open window thoracostomy for pleural empyema complicating partial lung resection. Ann Thorac Surg 2009;87:869-73.

76. Hollaus PH, Lax F, Janakiev D, et al. Endoscopic treatment of postoperative bronchopleural fistula: experience with 45 cases. Ann Thorac Surg 1998;66:923-7.

77. Tsunezuka Y, Sato H, Tsukioka T, et al. A new instrument for endoscopic gluing for bronchopleural fistulae. Ann Thorac Surg 1999;68:1088-9.

78. Baumann WR, Ulmer JL, Ambrose PG, et al. Closure of a bronchopleural fistula using decalcified human spongiosa and a fibrin sealant. Ann Thorac Surg 1997;64:230-3 .

79. Fiorelli A, Frongillo E, Santini M. Bronchopleural fistula closed with cellulose patch and fibrin glue. Asian Cardiovasc Thorac Ann 2015;23:880-3.

80. Ranu H, Gatheral T, Sheth A, et al. Successful endobronchial seal of surgical bronchopleural fistulas using BioGlue. Ann Thorac Surg 2009;88:1691-2.

81. Ponn RB, D'Agostino RS, Stern H, et al. Treatment of peripheral bronchopleural fistulas with endobronchial occlusion coils. Ann Thorac Surg 1993;56:1343-7.

82. Sivrikoz CM, Kaya T, Tulay CM, et al. Effective approach for the treatment of bronchopleural fistula: application of endovascular metallic ring-shaped coil in combination with fibrin glue. Ann Thorac Surg 2007;83:2199-201.

83. Watanabe S, Shimokawa S, Yotsumoto G, et al. The use of a Dumon stent for the treatment of a bronchopleural fistula. Ann Thorac Surg 2001;72:276-8.

84. Cao M, Zhu Q, Wang W, et al. Clinical Application of Fully Covered Self-Expandable Metal Stents in the Treatment of Bronchial Fistula. Thorac Cardiovasc Surg 2016;64:533-9.

85. Bellato V, Ferraroli GM, De Caria D, et al. Management of postoperative bronchopleural fistula with a tracheobronchial stent in a patient requiring mechanical ventilation. Intensive Care Med 2010;36:721-2.

86. Chae EY, Shin JH, Song HY, et al. Bronchopleural fistula treated with a silicone-covered bronchial occlusion stent. Ann Thorac Surg 2010;89:293-6.

87. Han X, Yin M, Li L, et al. Customized airway stenting for bronchopleural fistula after pulmonary resection by interventional technique: single-center study of 148 consecutive patients. Surg Endosc 2018;32:4116-24.

88. Snell GI, Holsworth L, Fowler S, et al. Occlusion of a broncho-cutaneous fistula with endobronchial one-way valves. Ann Thorac Surg 2005;80:1930-2.

89. Giddings O, Kuhn J, Akulian J. Endobronchial valve placement for the treatment of bronchopleural fistula: a review of the current literature. Curr Opin Pulm Med 2014;20:347-51.

90. Gaspard D, Bartter T, Boujaoude Z, et al. Endobronchial valves for bronchopleural fistula: pitfalls and principles. Ther Adv Respir Dis 2017;11:3-8.

91. Fiorelli A, D'Andrilli A, Cascone R, et al. Unidirectional endobronchial valves for management of persistent air-leaks: results of a multicenter study. J Thorac Dis 2018;10:6158-67.

92. Machida Y, Tanaka M, Motono N, et al. Successful 
treatment of bronchial fistula after pulmonary lobectomy by endobronchial embolization using an endobronchial watanabe spigot. Case Rep Pulmonol 2015;2015:425694.

93. Battistoni P, Caterino U, Batzella S, et al. The Use of Polyvinyl Alcohol Sponge and Cyanoacrylate Glue in the Treatment of Large and Chronic Bronchopleural Fistulae following Lung Cancer Resection. Respiration 2017;94:58-61.

94. Yamamoto S, Endo S, Minegishi K, et al. Polyglycolic acid mesh occlusion for postoperative bronchopleural fistula. Asian Cardiovasc Thorac Ann 2015;23:931-6.

95. Ishikawa K, Kato T, Aragaki M, et al. Endobronchial closure of a bronchopleural fistula using a fibrin gluecoated collagen patch and fibrin glue. Ann Thorac Cardiovasc Surg 2013;19:423-7.

96. Wang Z, Yu HB, Luo Q, et al. Treatment of Bronchopleural Fistula with Carbolic Acid instilled through Bronchofiberscope in post-pulmonectomy patients. J Cardiothorac Surg 2015;10:120.

97. Fuso L, Varone F, Nachira D, et al. Incidence and Management of Post-Lobectomy and Pneumonectomy Bronchopleural Fistula. Lung 2016;194:299-305.

98. Kramer MR, Peled N, Shitrit D, et al. Use of Amplatzer device for endobronchial closure of bronchopleural fistulas. Chest 2008;133:1481-4.

99. Fruchter O, Kramer MR, Dagan T, et al. Endobronchial closure of bronchopleural fistulae using amplatzer devices: our experience and literature review. Chest 2011;139:682-7.

100. Ottevaere A, Slabbynck H, Vermeersch P, et al. Use of an Amplatzer Device for Endoscopic Closure of a Large Bronchopleural Fistula following Lobectomy for a Stage I Squamous Cell Carcinoma. Case Rep Oncol 2013;6:550-4.

101.Fruchter O, El Raouf BA, Abdel-Rahman N, et al. Efficacy of bronchoscopic closure of a bronchopleural fistula with amplatzer devices: long-term follow-up. Respiration 2014;87:227-33.

102. Klotz LV, Gesierich W, Schott-Hildebrand S, et al. Endobronchial closure of bronchopleural fistula using Amplatzer device. J Thorac Dis 2015;7:1478-82.

103.Liu J, Li J, Cui F, et al. One-week recovery from bronchopleural fistula by combined techniques. J Thorac Dis 2018;10:E431-E434.

104. Scordamaglio PR, Tedde ML, Minamoto H, et al. Can total bronchopleural fistulas from complete stump dehiscence be endoscopically treated? Eur J Cardiothorac Surg 2017;51:702-8.

105.Haghshenasskashani A, Rahnavardi M, Yan TD, et al. Intrathoracic application of a vacuum-assisted closure device in managing pleural space infection after lung resection: is it an option? Interact Cardiovasc Thorac Surg 2011;13:168-74.

106. Sziklavari Z, Grosser C, Neu R, et al. Complex pleural empyema can be safely treated with vacuum-assisted closure. J Cardiothorac Surg 2011;6:130.

107. Babu A, Mitchell J. Technique of muscle flap harvest for intrathoracic use. Oper Tech Thorac Cardiovasc Surg 2010;15:41-52.

108. Llewellyn-Bennett R, Wotton R, West D. Prophylactic flap coverage and the incidence of bronchopleural fistulae after pneumonectomy. Interact Cardiovasc Thorac Surg 2013;16:681-5.

109. Ludwig C, Stoelben E. A new classification of bronchial anastomosis after sleeve lobectomy. J Thorac Cardiovasc Surg 2012;144:808-12.

110. Kawahara K, Akamine S, Takahashi T, et al. Management of anastomotic complications after sleeve lobectomy for lung cancer. Ann Thorac Surg 1994;57:1529-32; discussion 1532-3.

111. Rea F, Loy M, Bortolotti L, et al. Morbidity, mortality, and survival after bronchoplastic procedures for lung cancer. Eur J Cardiothorac Surg 1997;11:201-5.

112. Rea F, Marulli G, Schiavon M, et al. A quarter of a century experience with sleeve lobectomy for non-small cell lung cancer. Eur J Cardiothorac Surg 2008;34:488-92; discussion 492.

113. Abe J, Hasumi T, Takahashi S, et al. Fatal bronchopulmonary artery fistula after lobectomy for lung cancerdagger. J Surg Case Rep 2015;2015:rjv110.

114. Davison BD, Ring DH, Bueno R, et al. Endovascular stent-graft repair of a pulmonary artery-bronchial fistula. J Vasc Interv Radiol 2003;14:929-32.

115. Tedder M, Anstadt MP, Tedder SD, et al. Current morbidity, mortality, and survival after bronchoplastic procedures for malignancy. Ann Thorac Surg 1992;54:387-91.

116. Hinderberger P, Fliss B, Thali MJ, et al. Fatal bronchovascular fistula after lobectomy visualized through postmortem computed tomography angiography: A case report. Forensic Sci Med Pathol 2017;13:234-9.

117. Yildizeli B, Fadel E, Mussot S, et al. Morbidity, mortality, and long-term survival after sleeve lobectomy for non-small cell lung cancer. Eur J Cardiothorac Surg 2007;31:95-102.

118. Fadel E, Yildizeli B, Chapelier AR, et al. Sleeve lobectomy for bronchogenic cancers: factors affecting survival. Ann Thorac Surg 2002;74:851-8; discussion 858-9. 
119. Lewis RJ, Caccavale RJ, Bocage JP, et al. Video-assisted thoracic surgical non-rib spreading simultaneously stapled lobectomy: a more patient-friendly oncologic resection. Chest 1999;116:1119-24.

120.Lucchi M, Melfi F, Ribechini A, et al. Sleeve and wedge parenchyma-sparing bronchial resections in low-grade neoplasms of the bronchial airway. J Thorac Cardiovasc Surg 2007;134:373-7.

121.Maurizi G, Ciccone AM, Vanni C, et al. Reimplantation of the upper lobe bronchus after lower sleeve lobectomy or bilobectomy: long-term results. Eur J Cardiothorac Surg 2018;53:1180-5.

122. Van Schil PE, Brutel de la Riviere A, Knaepen PJ, et al. Completion pneumonectomy after bronchial sleeve resection: incidence, indications, and results. Ann Thorac Surg 1992;53:1042-5.

123. Bylicki O, Vandemoortele T, Orsini B, et al. Incidence and management of anastomotic complications after bronchial resection: a retrospective study. Ann Thorac

doi: 10.21037/shc.2020.03.09

Cite this article as: Wallwork K, Belcher E. Post-lobectomy airways complications. Shanghai Chest 2021;5:18.
Surg 2014;98:1961-7.

124. Faber LP, Jensik RJ, Kittle CF. Results of sleeve lobectomy for bronchogenic carcinoma in 101 patients. Ann Thorac Surg 1984;37:279-85.

125.Davini F, Gonfiotti A, Comin C, et al. Typical and atypical carcinoid tumours: 20-year experience with 89 patients. J Cardiovasc Surg (Torino) 2009;50:807-11.

126. Kutlu CA, Goldstraw P. Tracheobronchial sleeve resection with the use of a continuous anastomosis: results of one hundred consecutive cases. J Thorac Cardiovasc Surg 1999;117:1112-7.

127. Yatsuyanagi E, Hirata S, Yamazaki K, et al. Anastomotic complications after bronchoplastic procedures for nonsmall cell lung cancer. Ann Thorac Surg 2000;70:396-400.

128.Hong TH, Cho JH, Shin S, et al. Extended sleeve lobectomy for centrally located non-small-cell lung cancer: a 20-year single-centre experience. Eur J Cardiothorac Surg 2018;54:142-8. 